\title{
PARA ALÉM DA EPISTEMOLOGIA: REFLEXÕES NECESSÁRIAS PARA O DESENVOLVIMENTO DO CONHECIMENTO ${ }^{1}$
}

\author{
Deise Luiza da Silva Ferraz ${ }^{2}$ \\ Rossi Henrique Soares Chaves ${ }^{3}$ \\ Janaynna de Moura Ferraz ${ }^{4}$
}

http://dx.doi.org/10.1590/1413-2311.204.80474

\section{RESUMO}

Este ensaio objetiva analisar os limites das propostas gnosiológicas frente à contribuição da ontologia para o desenvolvimento do conhecimento e, em especial, para o conhecimento administrativo. Assim, procedemos uma análise da argumentação que consideramos ter produzido maior impacto na produção de conhecimento no campo administrativo brasileiro na atualidade, o "Círculo de Matrizes Epistêmicas" de Ana Paula Paes de Paula (2016). Partimos da apreciação das categorias de ontologia e gnosiologia buscando delimitá-las e confrontá-las para que pudéssemos contextualizar a Guerra Paradigmática que engendra a tese das matrizes. A análise nos mostra que a noção de "incompletude cognitiva" representa um estímulo para o avanço do conhecimento, como bem apontou a autora, contudo a solução proposta, os círculos epistêmicos, são incapazes de derruir a cisão entre os interesses técnicos, práticos e emancipatórios, pois mantém os cortes nos fenômenos sociais e opera gnosiologicamente, sendo fruto da construção da razão a partir de seus interesses. Como conclusões, recuperamos o estatuto ontológico fundante do ser social contrapondo a tradição filosófica habermasiana frente à apreensão ontológica materialista marxiana no intuito de

\footnotetext{
${ }^{1}$ Recebido em 20/02/2018, aceito para publicação em 21/06/2018.

${ }^{2}$ Universidade Federal de Minas Gerais (Belo Horizonte, MG, Brasil) - deiseluiza@,face.ufmg.br

${ }^{3}$ Universidade Federal de Minas Gerais (Belo Horizonte, MG, Brasil) - rossichaves@hotmail.com

${ }^{4}$ Universidade Federal do Oeste da Bahia (Bom Jesus da Lapa, BA, Brasil) - janaynna.ferraz@ufob.edu.br
} 
avançar na produção do conhecimento ao direcionar os esforços à primazia do objeto, isto é, na realidade das relações sociais apreendidas em sua totalidade.

Palavras-chave: Ontologia. Gnosiologia. Círculo das Matrizes Epistêmicas. Materialismo Histórico Dialético. Epistemologia

\title{
BEYOND EPISTEMOLOGY: REFLECTIONS NECESSARY FOR THE DEVELOPMENT OF KNOWLEDGE
}

\begin{abstract}
This essay aim is to analyze the limits of the gnosiological proposals in relation to the contribution of ontology to the development of knowledge and in particular to administrative knowledge. Thus, we proceed to an analysis of the argument that we consider having produced the greatest impact on the production of knowledge in the Brazilian administrative field, the "Circle of Matrices Epistemic" by Ana Paula Paes de Paula (2016). We start from the appreciation of the categories ontology and gnosiology trying to delimit them and confront them so that we could contextualize the Paradigmatic War that engenders the thesis of the matrices. The analysis shows that the notion of "cognitive incompleteness" represents an impetus for the advancement of knowledge, as the author has pointed out, but the proposed solution, epistemic circles, are incapable of demolish the division between technical and practical interests and emancipatory, because it maintains the cuts in the social phenomena and operates gnosiologically, being fruit of the construction of the reason from its interests. As a conclusion, we recover the foundational ontological status of the social being by contrasting the Habermasian philosophical tradition with the Karl Marx materialist ontological apprehension in order to advance in the production of knowledge by directing efforts to the primacy of the object, that is, in the reality of the social relations seized in its totality.
\end{abstract}

Keywords: Ontology, Gnosiology. Circle of Epistemic Matrices. Historical Dialectical Materialism. Epistemology.

\section{ADEMÁS DE LA EPISTEMOLOGÍA: REFLEXIONES NECESARIAS PARA EL DESARROLLO DEL CONOCIMIENTO}

REAd | Porto Alegre - Vol. 24 - No 2 - Maio / Agosto 2018 - p. 1-30 


\section{RESUMEN}

Este ensayo tiene por objetivo analizar los límites de las propuestas gnosiológicas frente a la contribución de la ontología para el desarrollo del conocimiento y, en especial, para el conocimiento administrativo. Así, procedimos un análisis de la argumentación que consideramos haber producido mayor impacto en la producción de conocimiento en el campo administrativo brasileño en la actualidad, el "Círculo de Matrices Epistémicas" de Ana Paula Paes de Paula (2016). Partimos de la apreciación de las categorías ontología y gnosiología buscando delimitarlas y confrontarlas para que pudiéramos contextualizar la Guerra Paradigmática que engendra la tesis de las matrices. El análisis nos muestra que la noción de "incompletud cognitiva" representa un estímulo para el avance del conocimiento, como bien apuntó la autora, sin embargo, la solución propuesta, los círculos epistémicos, son incapaces de derruir la escisión entre los intereses técnicos, prácticos y emancipatorios, pues mantiene los cortes en los fenómenos sociales y opera gnosiológicamente, siendo fruto de la construcción de la razón a partir de sus intereses. Como conclusiones, recuperamos el estatuto ontológico fundante del ser social contraponiendo la tradición filosófica habermasiana frente a la aprehensión ontológica materialista marxiana con el fin de avanzar en la producción del conocimiento al dirigir los esfuerzos a la primacía del objeto, es decir, en la realidad de las relaciones sociales incautadas totalidad.

Palabras-clave: Ontología. Gnosiología. Círculo de las Matrices Epistémicas. Materialismo Histórico Dialéctico. Epistemología.

\section{INTRODUÇÃO: EPISTEMOLOGIA NAS CIÊNCIAS ADMINISTRATIVAS}

Com esta escrita tomamos parte no que tem sido chamado de Guerra Paradigmática. No campo das Ciências Administrativas, o texto de Burrell e Morgan (1979) teria criado a condição para o decreto dessa peleja que se estende até os dias de hoje. Porém, Paes de Paula (2016), almejando decretar a paz, propôs como solução o Círculo das Matrizes Epistêmicas (CME). Seria este modelo a condição necessária para eliminar do processo de construção do conhecimento, os conflitos e disputas existentes? Eis a questão que nos move a realizar a crítica da proposta do Círculo das Matrizes Epistêmicas perscrutando o primado gnosiológico do estatuto científico frente à práxis científica marxiana. 
Em outras palavras, objetivamos analisar os limites das propostas gnosiológicas frente à contribuição da ontologia marxiana para o desenvolvimento do conhecimento. Dada a impossibilidade de tecer tal exame radical da ciência em geral no espaço de um artigo, nos limitamos ao campo da Administração, atendendo ao chamado de Campos (1997), Faria (2015, 2016), Paes de Paula (2015, 2016), Serva (2013), dentre outros, para a necessidade de desenvolver a capacidade explicativa do conhecimento administrativo. Entendemos que não há como atender essa demanda sem romper, necessariamente, com a perspectiva gnosiológica num movimento de apreender a determinação ontoprática do pensamento. Nesse sentido, por meio da proposta de Paes de Paula (2016) buscamos demonstrar como as alterações no modo de produzir conhecimento restrita ao âmbito da gnosiologia, cujo primado é sempre do sujeito, são insuficientes para promover uma transformação social que vise à emancipação humana. Pois, se por um lado a perspectiva gnosiológica possibilita distintas explicações para os fenômenos, por outro é incapaz de alcançar o cerne da problemática: o real, em outras palavras, o ser do objeto, conforme sustentamos no decorrer deste texto.

Consideramos a relevância da proposta de Paes de Paula (2016) por ela sustentar novas pesquisas desenvolvidas por pesquisadores de diferentes regiões do país (SCUSSEL, 2017; SANTOS, 2017; ALCÂNTARA et al, 2018) - ademais, o texto já foi citado por outros 17 trabalhos desde sua publicação até então -, outrossim, a autora se propôs a superar “a taxonomia criada por Burrell e Morgan (1979) [que] ainda exerce sua influência no campo da Administração até os dias atuais" (BARBOSA et al, 2013, p. 642). Assumimos assim a tarefa de analisar a proposta do CME sem nos estendermos na proposta de Burrel e Morgan por entendermos que as críticas a proposta dos últimos foram desenvolvidas com competência por vários pesquisadores da área, o que inclui, Paes de Paula (2015).

Este ensaio está estruturado da seguinte maneira: o primeiro tópico traz uma breve revisão das categorias gnosiologia e ontologia; dada a relevância da compreensão das perspectivas que apontamos. No segundo procedemos à análise da proposta de Paes de Paula, no terceiro buscamos refletir acerca da contribuição da perspectiva ontológica marxiana para superação dos problemas sintetizados pela autora enquanto disputas entre paradigmas.

\section{ONTOLOGIA E GNOSIOLOGIA: UM POUCO MAIS DO QUE VERBETES PARA CONTEXTUALIZAR A GUERRA PARADIGMÁTICA}

A gnosiologia-epistemologia remete à qualidade presente na subjetividade ou no sujeito cognitivo, operando como imputação subjetiva sobre a realidade. Essa teoria do 
conhecimento tem suas raízes em autores como Descartes e Kant - através de suas reviravoltas subjetiva-epistemológicas, mais precisamente no seu idealismo subjetivo, como coloca Chasin (2009). E o que significa isso? Simplificadamente, significa que o conhecimento é uma qualidade do sujeito que tem uma ideia sobre o real, permitindo, portanto, classificá-lo, mensurá-lo, etc. Nesse contexto, a razão aparece como a instância que permite estabelecer e delimitar a rede de conexões das coisas, como objeto do sujeito. A verdade, o ser, fica circunscrito à construção da subjetividade. A realidade é concebida sempre na dependência da subjetividade, existindo na capacidade subjetiva de percebê-la, de pensá-la. O conhecimento do sujeito sobre o real não é uma apropriação do real em sua imanência e totalidade, mas uma apresentação organizada pela razão, segundo critérios colocados pela própria razão sobre o objeto. Neste sentido, o posicionamento gnosiológicoepistemológico se preocupa com a constituição do saber pela propositura subjetiva, está preocupado com o "como saber?" e, deste modo, ganha relevância a discussão metodológica - os procedimentos/critérios envolvidos no processo de verificação da ideia do real como empírico.

No desenvolvimento da produção de conhecimento, esse será tão mais válidos quanto tais critérios forem rigorosamente aceitos, eis porque o consenso entre os sujeitos pesquisadores se torna o fundamento de verdade científica, eis o solo do acirramento das disputas em torno de quais critérios são os válidos. Assim, temos uma ciência que parte exclusivamente do sujeito-pesquisador, que opera a perda da coisa, do ser, da integralidade do real, eis porque nesta perspectiva científica as explicações aos problemas acabam sendo distintas e, portanto, apreendidas enquanto uma rivalidade entre os sujeitos operadores da ciência.

Na ontologia, por sua vez, a preocupação central é com o ser, com "o que é?", com a natureza do objeto, isto é, sua totalidade real objetiva. A ontologia busca compreender o ser das coisas enquanto tais, consiste na totalidade objetiva em toda sua independência da intelecção. O real existe e tem sua autonomia em relação ao conhecimento que o sujeito (ser humano) tem dele. Porém, o conhecimento que o ser humano possui, o permite interferir no real, modificando-o, e isto está posto tanto para as relações causais (aquelas que reconhecemos serem objetos de estudos das ciências naturais) quanto para as relações de causalidades postas (aquelas que reconhecemos serem objetos de estudos das ciências humanas, sociais, etc.) (LUKÁCS, 2012).

Portanto, na perspectiva da ontologia, o sujeito que conhece não constrói seu objeto por meio de ideias e depois classificá-lo, mensurá-lo, verificá-lo confrontando a ideia com o 
empírico, isto é, não há oposição entre teoria e prática. Na perspectiva ontológica, o real imputa ao sujeito o seu ser. O ser do objeto não é aquilo que é porque nossa razão assim o construiu, o real é independente de nossa razão e sensibilidade, e quando o sujeito apreende cognitivamente o ser do objeto, temos o objeto transposto para o pensamento, temos o conhecimento do ser do objeto. Nesse sentido, é o ser do objeto que dirá o que necessitamos para conhecê-lo e não as qualidades de nossa razão, ainda que elas estejam presentes no processo.

Buscamos demonstrar como a questão ontológica e a questão gnosiológicaepistemológica são bastante diferentes. A ontologia está na afirmação do ser enquanto tal, é totalidade objetiva em toda independência da intelecção. A gnosiologia-epistemologia, no que lhe concerne, é uma preocupação necessariamente subjetiva, colocada estritamente no círculo do sujeito cognitivo.

Essa centralidade do sujeito pode ser observada nos Estudos Organizacionais ou nas Ciências Administrativas (como queiram) por meio do que Barbosa et al (2013) e Paes de Paula (2016) chamam de Guerra Epistemológica, que teriam sua origem no trabalho de Burrell e Morgan (1979), cujas raízes provém de Thomas Kuhn (2007).

A guerra paradigmática, que segundo Paes de Paula $(2015 ; 2016)$ seria um obstáculo ao desenvolvimento do conhecimento no campo das ciências sociais e, em especial, dos estudos organizacionais, foi apontada por outros autores como um problema para o campo. Os paradigmas dão aos pesquisadores uma ideia de terreno a ser protegido contra os invasores (BURKE, 2003), gerando uma fragmentação - e disputas - nos estudos organizacionais (SIEGLER; BIAZZIN; FERNANDES, 2014). Ou ainda, como observa Barbosa et al (2013, p. 1):

A discussão sobre abordagens paradigmáticas no campo da Administração pode ser profícua quando provoca os pesquisadores a refletir sobre premissas, práticas e valores compartilhados por uma comunidade científica. Entretanto, ao extremo, torna-se uma disputa que impede a busca de outras abordagens para lidar com a complexidade dos fenômenos sociais.

Em resumo, as críticas que Paes de Paula (2016) tece à Burrell e Morgan, dada a sua apropriação de Kuhn, centram-se sob aspectos como: os parâmetros utilizados para as ciências da natureza não se aplicam às ciências sociais - o que invalida a ideia de paradigmas, posto que nas ciências sociais não são construídos modelos ou exemplos a serem aplicados à resolução de problemas; invalidada a noção de paradigma, invalida-se a incomensurabilidade entre eles, logo, a revolução científica apresentada por Kuhn (2007) como a responsável pelo avanço do conhecimento não seria o movimento das ciências sociais. 
Para Paes de Paula (2016) é necessário que o campo dos Estudos Organizacionais abandone as noções apresentadas por Burrell e Morgan (1979), neste ponto concordamos com a autora, é profícuo superar os paradigmas. Paes de Paula $(2015 ; 2016)$ segue, respaldada em Habermas e Hill, para propor uma teoria do desenvolvimento do conhecimento para as ciências sociais viabilizada pela perspectiva das Matrizes Epistemológicas, no lugar da guerra paradigmática construída pela incomensurabilidade entre paradigmas, a matriz permite a construção de pontes entre as epistemes por meio do reconhecimento da incompletude cognitiva, pois "não é o fato de 'vencer o adversário paradigmático' com uma nova revolução científica que faz o conhecimento avançar, e sim a busca por contemplar outros interesses cognitivos, trazendo novas explicações dos fenômenos e novas soluções para os problemas sociais". (PAES DE PAULA, 2016, pp. 3839 ), porém neste ponto, não estamos de acordo com a autora, conforme exporemos a seguir.

Seria então, a proposta de Paes de Paula a solução para o problema apontado por Guerreiro Ramos e Costa? Indagando de outra forma: o Círculo de Matrizes Epistêmicas poderia ser o meio para recuperar o poder explicativo das teorias organizacionais? Nossa resposta é: sim e não. Para explicar, precisamos adentrar no argumento da autora para demonstrar que ao se manter no campo da episteme, sua Matriz permite, por um lado, uma nova arma discursiva na guerra epistemológica colaborando para que alguns pontos do real sejam observados com maior liberdade - um avanço. Por outro, a Matriz demonstra a necessidade de rompermos com a perspectiva gnosiológica para que nossas teorias tenham poder explicativo sobre o real e, mais do que isso, nos permitam transformar o real.

\section{O CÍRCULO DAS MATRIZES EPISTEMOLÓGICAS E O PRIMADO GNOSIOLÓGICO}

O primeiro movimento realizado por Paes de Paula para desenvolver uma teoria do desenvolvimento do conhecimento alternativa à proposta de Burrell e Morgan (1979) foi sustentar-se nas colocações de Habermas sobre o desenvolvimento do conhecimento. Se para Kuhn (2007), autor utilizado por Burrel e Morgan (1979), o conhecimento se desenvolve pelas revoluções, para Habermas se desenvolve pela mobilização de interesses cognitivos, sendo esses os interesses técnicos (ciências naturais), os práticos (ciências do espírito) e os emancipatórios (filosofia). A dinâmica entre esses interesses "é animada pela dialética, ou seja, ainda que contraditórios, esses interesses deveriam constituir a unidade do conhecimento, pois os fenômenos sociais se apresentam de acordo com uma conjugação de 
interesses, uma vez que não há como separar o técnico, o prático e o emancipatório" (PAES DE PAULA, 2016, p. 33).

Após colocar a dialética como a lógica de mobilização dos três interesses que desenvolvem o conhecimento, Paes de Paula assume as colocações de Hill - que também nega a existência de paradigmas para as ciências sociais - afirmando que há "diferentes sistemas de produção de conhecimento, que envolvem questões epistêmicas, axiológicas e ideológicas" (PAES DE PAULA, 2016, p. 33). Vale destacar que os sistemas de produção de conhecimento são as diferentes perspectivas filosóficas, metodológicas e teóricas; que eles são autônomos entre si e cada um deles é responsável pela manutenção de sua coerência interna, reconhecendo que as visões de mundo meta-científicas, as metodologias e as teorias que compõem cada um deles são interdependentes. Além dessas afirmações, Paes de Paula (2016, p. 34) chama a atenção para uma observação de Hill: "há muitas possibilidades de construção de novos sistemas de conhecimento", desde que "os parâmetros que definem um sistema de produção de conhecimento" estejam presentes e, tenham consistência e "independência epistemológica que o singularize".

Deste modo, Paes de Paula (2016, p. 34) vê a solução para o dilema posto pela guerra paradigmática: crer "que não há limites em relação ao número de sistemas de produção de conhecimento que se pode desenvolver". Nesse caso, a autora refuta a guerra paradigmática assumindo que a crença na capacidade ilimitada da cognição humana na articulação dos elementos permitirá esvaziar a luta pela hegemonia de um determinado sistema e/ou paradigma.

Vale destacar que Burrell e Morgan (1979) não ignoram que há diferentes paradigmas, eles aceitaram que há modos distintos de explicar o mundo, e observaram que eles concorrem entre si. Assim, não nos parece ser suficiente crer que não há limites ao número de sistemas de produção do conhecimento, para romper com a guerra paradigmática. Até porque, se não há limite quanto ao número, Hill (1984, p. 65) aponta que há limite quanto aos sistemas, posto que cabe à cada sistema ser "responsável epistemologicamente apenas por suas próprias regras de organização e lógica”. O autor alerta que a consistência interna é algo que deve ser preservado e, nesse sentido, é responsabilidade dos pesquisadores não introduzirem elementos perturbadores da lógica interna que torna cada sistema autônomo. E, nesse sentido, esclarece que os adeptos de um sistema são responsáveis por: “(a) articular completamente os elementos de um sistema, (b) examinar as inconsistências internas do sistema, (c) propor soluções para as inconsistências quando elas são descobertas, e (d) 
identificar claramente e publicizar qualquer inconsistência que não seja sanada pelas soluções encontradas".

Logo, Hill defende que as respostas para as inconsistências de cada sistema sejam encontradas no próprio sistema por meio do que ele chama de "escavação e reconstrução de elementos perdidos do sistema de produção de conhecimento" (1984, p. 65). O autor pontua a necessidade da manutenção da autonomia entre os sistemas de produção. Demonstra que um sistema de produção de conhecimento necessita ter uma articulação própria que se caracteriza pelos limites dos elementos que se encadeiam e, nesse sentido, a discussão sobre a legitimidade de cada articulação está posta, o que envolve, inclusive, reconhecer que pode existir a incomensurabilidade. Paes de Paula (2015) não se detém nessa discussão, assume o argumento da viabilidade de construir sistemas de produção do conhecimento distintos e que esses sistemas não carecem eliminar um ao outro para existir. A autora segue sua argumentação pela superação das disputas entre pesquisadores, pois atentou-se a observação de Hill de que a consistência epistemológica de cada sistema deve ser julgada pelas suas próprias regras. Entretanto, o autor também aponta: "Esta posição não argumenta, entretanto, por um estado de anarquia intelectual, no qual "vale tudo" (HILL, 1984, p. 65). O autor indica, sem desconsiderar as colocações de Kuhn (2007), a necessidade de revoluções científicas para determinadas crises e que o desenvolvimento do conhecimento nas ciências sociais pode ocorrer por mudanças sub-revolucionárias intrassistemas, pela realocação de seus elementos.

Em suma, Hill chama a atenção para a possibilidade da coexistência de distintos sistemas de produção (paradigmas). Acontece que a guerra paradigmática não está posta pelo direito de existir enquanto conjunto de pensamento (ciência e religião coexistem enquanto conjunto de pensamento), mas em ser reconhecido como uma Ciência pelos agentes produtores do conhecimento e, quando o conhecimento é produzido a partir da centralidade da razão (da crença), o reconhecimento envolve convencimento, e o convencimento envolve discussões, disputas e lutas. Temos aqui, a primeira manifestação de que para se romper com as guerras paradigmáticas ou de sistemas de produção de conhecimento, precisamos superar a imputação da cognição sobre o real.

Mantendo-se na perspectiva gnosiológica, o segundo movimento da autora para a nova teoria do desenvolvimento do conhecimento foi apresentar um modelo: o Círculo das Matrizes Epistêmicas. O CME é a unidade do conhecimento, por ser a unidade de três matrizes epistêmicas e, assim o Círculo é apresentado como um novo modelo para resolver o problema do desenvolvimento do conhecimento. No lugar de paradigmas sociológicos, 
abordagens sociológicas produzidas a partir dos elementos que compõem a CME. De forma sintética, apresentamos o conteúdo (filosofia, lógica, interesse) de cada uma das três matrizes em suas especificidades.

I) A matriz empírico-analítica é guiada por uma filosofia positiva, por uma lógica formal conduzida por valores de conhecimento útil, controle e predição (interesse técnico). Busca explicações causais e adota uma postura de neutralidade axiológica. Assemelha-se ao atual paradigma funcionalista e é utilizada por parte considerável dos estudos na Administração. De forma bastante simplificada - abstraindo as nuances de cada pensador dessa perspectiva - vale relembrar que aquilo que está posto aqui é: o mundo, objeto posto frente ao sujeito, é captado por nossos sentidos e organizado por nossa intelecção (razão). É por organizá-lo que ele se apresenta como existente, como real. Como os sentidos podem nos enganar, cabe a razão ser o vigia do que conhecemos e esta segue a lógica formal. $\mathrm{O}$ que conhecemos não é o ser do objeto, pois o objeto se oferece aos sentidos numa relação de efeitos (causalidades), cabendo a razão traçar o caminho que revela as causas, expressando-as em leis que possibilitam a previsão dos próprios fatos. Na filosofia positiva, só é ciência o que está posto dessa maneira.

II) A matriz hermenêutica e sua filosofia hermenêutica usam de lógica interpretativa, cujas palavras e símbolos têm grande relevância para a explicação da realidade, mais do que isso, eles são a realidade. $\mathrm{O}$ interesse que guia essa matriz é o prático. O que está posto, em última instância, não é o objeto existente independente do sujeito cognoscível, mas o objeto só é, porque é um significado, porque a ele, o sujeito cognoscível atribuiu um significado. O significado é um ato de ação e não simplesmente um ato mental, o interesse dessa matriz, portanto, não poderia ser outro se não a prática, mas especificamente, os sentidos da prática. Rejeita o objetivismo, visto que a compreensão é processo intersubjetivo. A metodologia deve refletir as regras da prática da pesquisa, buscando estabelecer conexões epistêmicas significativas ao invés de submeter-se a princípios abstratos válidos para deduções e linguagem formalizada.

III) A matriz crítica, ao seu turno, inspira-se numa filosofia negativa, não quer o rigor no sentido das proposições - lógica formal -, mas as contradições. Sua lógica é dialética e reivindica um interesse emancipatório. Cabe destacar que a contradição, na concepção da dialética negativa adotada por Paes de Paula (2016), se dá no pensamento e que a emancipação é da ciência em relação ao dogmatismo, pois se trata de uma emancipação das ideias posto que elas têm a primazia sobre a materialidade. Essa consideração será retomada na explicitação da concepção da dialética no Materialismo Histórico no tópico 3 deste texto. 
Após apresentar a filosofia, a lógica e o interesse que estão em cada matriz epistêmica, a autora pondera sobre a escolha do círculo enquanto figura que expressa seu modelo, sua escolha está pautada na matriz hermenêutica.

O quadrado é comumente associado ao pensamento cartesiano, analítico e mecânico, indicando precisão, cálculo e perfeição matemática. Ele ainda simboliza a interrupção do movimento, pois os quatro ângulos indicam descontinuidade no fluxo, inércia e limitação. O quadrado ainda é uma forma construída que não se encontra na natureza, também remetendo à rigidez, estabilidade e ordem. O círculo, por sua vez, é associado ao pensamento orgânico, relacionando-se ao incalculável e ao natural. Ele simboliza a fluidez livre e sem interrupções. O círculo é uma forma abundante na natureza e faz referência à flexibilidade, ao infinito, ao ilimitado e à ideia de totalidade (PAES DE PAULA, 2015, p. 117).

Considerando, portanto, que o círculo representaria uma totalidade, ele é o símbolo ideal do "lócus a partir do qual as abordagens sociológicas se orientam" (PAES DE PAULA, 2016, p. 37). Para a autora, as matrizes epistêmicas dispostas em um círculo representam a totalidade das ilimitadas possibilidades de construção de sistemas produtivos de conhecimento ou de abordagens sociológicas que abarcam os interesses técnicos, práticos e emancipatórios. Seguindo o pensamento de Habermas, a autora indica a indissociabilidade dos interesses, porém, dá primazia a matriz hermenêutica, "Essa nova forma de fazer ciência parte do princípio de que a hermenêutica deveria ser, como Jürgen Habermas (1968/1982) reivindica, uma ciência universal" (PAES DE PAULA, 2016 p. 38).

Após essa afirmação, necessitamos retornar, ainda que brevemente, a guerra paradigmática: não é justamente a pretensão do positivismo - em sua manifestação funcionalista no campo da Administração e dos Estudos Organizacionais - de ser "a ciência" o determinante das disputas efetuadas pelos demais paradigmas pelo reconhecido de ser também ciência? Advogar pela matriz hermenêutica como "ciência universal" não é apenas outra forma de expressar a mesma luta? Mas, há uma diferença, a lógica da ciência positiva não pode reconhecer outras formas de produzir conhecimento como ciência sem se refutar como ciência, por sua vez, como a hermenêutica valoriza o significado, as ciências, portanto, seriam as práticas que significamos como tal, nessa produção intersubjetiva, é possível falar em várias ciências, desde que, a hermenêutica seja a universal. Seguimos, portanto, num jogo de convencimentos sobre a qual crença nos filiamos: uma rechaça a diferença, a outra, tolera. 
Um ponto usado pela autora para defender a supremacia da hermenêutica sustenta-se na diferença da natureza dos objetos das ciências naturais e das ciências humanas/sociais. Paes de Paula (2016) mantém-se na continuidade da crítica efetuada a Kuhn: a impossibilidade de trazer para as ciências humanas a lógica das ciências da natureza. Por trás de toda essa discussão, temos, portanto, a permanência da velha dicotomia entre a natureza do natural e a natureza do cultural, dicotomia que é um falso problema quando a prioridade é o ser do objeto.

Voltando as colocações da autora:

No domínio das ciências naturais, temos uma concordância sobre o uso de um modelo ou exemplo a ser replicado para solução de problemas que, como propõe Thomas Kuhn, quando é perturbado, faz surgir uma incomensurabilidade a partir da qual pode ocorrer uma revolução científica e emergir um novo paradigma. Ora, o conhecimento nas ciências sociais e nos estudos organizacionais não se desenvolve devido a rivalidades paradigmáticas, incomensurabilidades e revoluções científicas, mas porque na investigação de fenômenos sociais, ocorrem incompletudes cognitivas que levam os pesquisadores a buscarem outras teorias, metodologias, abordagens sociológicas, ou mesmo outras matrizes epistêmicas. Não é o fato de "vencer o adversário paradigmático" com uma nova revolução científica que faz o conhecimento avançar, e sim a busca por contemplar outros interesses cognitivos, trazendo novas explicações dos fenômenos e novas soluções para os problemas sociais (PAES DE PAULA, 2016, pp. 38-39).

Em resumo, para Paes de Paula, o avanço ocorre pelas reconstruções epistêmicas nos sistemas produtivos de conhecimento, denominados pela autora de abordagem sociológica. As abordagens podem ser puras ou híbridas (seria referência às ciências da natureza?). As abordagens sociológicas puras são aquelas que articulam tão somente a filosofia, a lógica e o interesse de cada matriz, porém, nessa construção é possível construir teorias e metodologias que se aproximam das outras matrizes criando a possibilidade de reconstruções epistêmicas avançadas. Sendo essas as responsáveis pela produção de abordagens sociológicas híbridas, cuja capacidade reside em "realizar interconexões entre as matrizes epistêmicas, contemplando mais de um interesse cognitivo" (PAES DE PAULA, 2016, p. 39). 
A comprovação de que a nova teoria do desenvolvimento do conhecimento apresentada pela autora corresponde ao desenvolvimento do conhecimento é um estudo elaborado por ela nas principais revistas nacionais e internacionais da área das Ciências Administrativas, bem como em anais de eventos. Ela analisou artigos publicados desde 1990 e constatou que os pesquisadores, quando não conseguem explicar determinado aspecto do fenômeno (incompletude cognitiva), operam reconstruções epistêmicas e, com isso, a ciência segue se desenvolvendo. Porém, Paes de Paula (2016) nada disse sobre os critérios apontados por Hill (1984) para a produção de sistemas novos de produção do conhecimento. No campo dos Estudos Organizacionais e das Ciências Administrativas, essas novas abordagens sociológicas híbridas teriam consistência entre seus elementos de acordo com as próprias regras de organização e lógica? Não nos alongaremos neste ponto, porque não é nosso objetivo aqui analisar as inconsistências de cada abordagem sociológica, seja ela pura ou híbrida, mas problematizamos a necessidade da primazia do real para o desenvolvimento de um conhecimento que o apreenda em sua totalidade e que possibilite intervenções de modo a superar os problemas sociais, pois, enquanto ficarmos nos limites da epistemologia estaremos apenas nos confrontando constantemente com nossas incompletudes cognitivas.

Ainda que Paes de Paula não tenha realizado essa guinada, permanecendo, portanto, na tradição gnosiológica, duas questões presentes no modelo do CME precisam ser destacadas, quais sejam: a incompletude cognitiva e os distintos interesses que guiam a produção do conhecimento. Passaremos a elas.

A noção de "incompletude cognitiva" representa um impulso para o avanço do conhecimento, mas se torna uma limitação diante da investigação de fenômenos sociais. Entendemos que quando Paes de Paula identifica tal incompletude, ela revela a questão da impossibilidade do intelecto de apreender todos os elementos do real, por trás dessa observação reside a crítica de que não há corte de objeto que possa dar conta da complexidade das relações sociais se houver a permanência dos limites dos paradigmas, por isso a necessidade de resgatar a categoria totalidade. A autora visualiza essa saída, entretanto opta por seguir gnosiologicamente efetuando cortes nos problemas sociais por meio de reconstruções, sempre tendo como horizonte o mais alto princípio axiológico, visando atender a questão principal de "buscar estratégias cognitivas que produzam um saber utilizável técnica, prática e emancipatoriamente” (PAES DE PAULA, 2015, p. 135), ou seja, a totalidade do objeto, para Paes de Paula, segue sendo fruto da construção da razão a partir de seus interesses. 
Em suma, a autora resume a questão principal às estratégias cognitivas e furta-se de questionar acerca da intencionalidade da práxis científica: saber utilizável tecnicamente por quem e para quê? Práticas que são resultados de quais determinantes? A alteração ou manutenção de uma ou outra prática atende às necessidades de quê (ou de quem)? Ou em termos mais diretos: para quem e para que servem as ciências sociais, especialmente as teorias das organizações? Emancipar o conhecimento da dogmática é suficiente para emancipar os seres humanos das condições de exploração e opressão em que vivem? Essas questões não podem ser postas no horizonte da nova teoria do conhecimento apresentada por Paes de Paula sob o risco de fazer ruir sua proposta e de trazer a tona a fragilidade da crítica habermasiana à categoria totalidade na perspectiva ontológica de Marx, conforme faremos no tópico seguinte, mas, antes disso, precisamos demonstrar as condições para a produção do conhecimento.

Colocar na primazia sobre o sujeito a condição real de produção do conhecimento significa observar que nessas disputas que ocorrem por meio do discurso da (in)comensurabilidade existem sujeitos que estão concorrendo por verbas de pesquisas. Apenas à guisa de exemplo, no Brasil, segundo o censo do Ministério da Educação, somos mais de 140 mil doutores, conforme a tabela 1.

Tabela 1- Número de Doutores no Brasil por Região

\begin{tabular}{|c|c|c|c|c|c|c|c|}
\hline \multirow[t]{3}{*}{ Região / UF } & \multicolumn{7}{|c|}{ Doutores (1) } \\
\hline & Censo & Censo & Censo & Censo & Censo & Censo & Censo \\
\hline & 2000 & 2002 & 2004 & 2006 & 2008 & 2010 & 2014 \\
\hline Norte & 705 & 1.152 & 1.721 & 2.313 & 2.863 & 3.877 & 6.863 \\
\hline Nordeste & 3.705 & 5.168 & 7.294 & 9.380 & 11.625 & 15.445 & 26.467 \\
\hline Sudeste & 17.354 & 20.540 & 28.837 & 33.900 & 38.558 & 45.991 & 66.702 \\
\hline Sul & 5.034 & 7.165 & 10.312 & 12.711 & 14.931 & 18.516 & 28.612 \\
\hline C. Oeste & 1.873 & 2.404 & 3.632 & 4.339 & 5.379 & 7.400 & 11.628 \\
\hline Total & 27.662 & 34.349 & 47.971 & 57.586 & 66.785 & 81.725 & 140.272 \\
\hline
\end{tabular}

Fonte: Censo do Ministério da Educação (2014). 
Houve um salto de 27.662 doutores, em 2000, para 140.272, em 2014. Cerca de 60 mil a mais entre os anos 2010 e 2014. Se por um lado é positivo o crescimento quantitativo, por outro lado não há garantias que a qualidade das pesquisas acompanhará a mesma progressão, tanto no que tange às condições para se pesquisar no Brasil, quanto no que refere à finalidade destes estudos.

Somente nas universidades públicas, em regime integral de trabalho, éramos, em 2014, 116.603 professores e professoras - se considerarmos Institutos Federais e Centros Tecnológicos, esse número sobe para 135.213; podemos acrescentar ainda os 24.232 empregados nas instituições privadas. Há, somente nas universidades públicas 85.982 doutores. Ressaltamos que o apoio à pesquisa se diferencia em universidades públicas em relação às particulares, seja pela jornada de trabalho, seja pelo incentivo financeiro pela publicação ou seja pelo fim pelo qual dado estudo é realizado, a escolha de um paradigma precisa estar vinculado à possibilidade de produzir; e corre-se o risco de não cumprir as metas de produtividade.

Considera-se que a maioria desses docentes estão inseridos em grupos de pesquisas, pela natureza de seus vínculos de trabalho. Ao cruzarmos tais dados com os do Apoio à Pesquisa, neste mesmo período, oferecido pelo Conselho Nacional de Desenvolvimento Científico e Tecnológico (CNPq), observamos que apenas 10.066 docentes foram beneficiários do programa. Considerando a Bolsa Produtividade em Pesquisa, são apenas 16.045 profissionais. Consideramos como ano de referência o ano de 2014, por ser este o que teve o maior investimento no período de 2001 a 2017. No ano de 2017, por exemplo, o número de bolsistas produtividade em pesquisa caiu para 15.877 e o apoio à pesquisa despencou para 159 beneficiários, vale destacar que no ano de 2016, pela inexistência de editais, não houve beneficiários para esse programa. Em outro exemplo, no ano de 2017, 2.218 projetos de pesquisadores mineiros foram submetidos ao Edital Universal da Fundação de Amparo à Pesquisa do estado, destes, apenas 692 propostas foram financiadas.

Em um ambiente em que há poucos recursos e os mesmos são destinados às propostas que melhor atenderem os interesses da produção de valor - vide a exigência nos critérios de avaliação da possibilidade de produção tecnológica e registros de patentes - , não é nada surpreendente que os pesquisadores tenham a tendência de rechaçar as pesquisas alheias e, um meio para isso, é alçar sua perspectiva como a universal, ainda que, em alguns casos, o argumento para tal seja refutar as metanarrativas. 
Estamos buscando apresentar, ainda que de modo incipiente, como a condição real da produção do conhecimento está muito além das discussões sobre o CME, ou seja, não é uma questão de interesses cognitivos. Precisamos observar que a métrica tem sido, sobretudo, nas Ciências Administrativas a chamada 'produção qualificada' - número de artigos em revistas Qualis A1 e A2. Entretanto, na nossa área são raras as revistas nesses estratos que estão sob a gerência de pesquisadores brasileiros, o que eleva sobremaneira a competição entre autores para a publicação e, nesse sentido, com pareceres emitidos por pares, a disputa pelo modo de fazer ciência é a argumentação central para realizar uma reserva de mercado, como diriam os economistas.

Duayer (2014), numa crítica à proposta de filosofia da ciência de Kuhn (2007) segundo a qual o cenário revolucionário sempre tende a substituir os paradigmas dominantes através das mudanças de paradigmas que se tornam incomensuráveis, puxada pela prioridade da reconfiguração na forma de explicar o mundo - aponta que a discussão ontológica é ignorada pela simples recusa da reflexão da procedência e da natureza objetiva dos paradigmas. Nesse contexto, para Duayer (2014, s/p), "la crítica es imposible", pois "la verdad no importa, pues es inalcanzable. Por consiguiente, la ciencia solo puede legitimarse por su eficacia como instrumento de la praxis inmediata.". Nesse sentido, a crítica de Duayer (2014) também é pertinente à proposta do CME, pois ao centrar-se na supremacia de interesses cognitivos para a construção do conhecimento, é impossibilitado um panorama de crítica em busca da verdade objetiva.

Dando a primazia para a condição da produção do conhecimento - que não se dá apenas no âmbito das discussões sobre a comensurabilidade, mas que passa por ela também podemos apreender melhor as disputas entre os pesquisadores e indicar que, para sua cessação, necessitamos romper com a lógica de financiamento de pesquisa. Necessitamos, portanto, revolucionar, de modo concreto nossas relações de produção científica, e, não apenas no âmbito do pensamento. Ao colocar o real da produção do conhecimento no centro do saber, observamos que as guerras paradigmáticas se dão em nome da manutenção do processo de valorização - e por isso, o ignora -, sobretudo em um estágio do desenvolvimento das forças produtivas em que a ciência tem assumido certo protagonismo no processo de valorização.

Para dar outro exemplo, basta observarmos o conhecimento produzido dentro do campo de gestão de pessoas e comportamento organizacional. Os pesquisadores dessa área, até mesmo os que se colocam como contrários as mazelas as quais são submetidos os trabalhadores, ao estudarem seus objetos observam somente um aspecto do fenômeno, 
enquanto assumem o outro como natural. Em geral, os pesquisadores conseguem descrever as relações de trabalho e seus desdobramentos para o prazer e sofrimento no trabalho, para o adoecimento, para o comprometimento, para os elementos de motivação, para os dilemas da carreira versus família, para a produção de identidades que resultam das relações com o trabalho. Porém, todos esses estudos são, conforme apontado por Ferraz (2016), para garantir o outro aspecto do fenômeno: o processo de valorização do valor. Vemos aqui mais uma vez, que ainda que esses pesquisadores enveredem por paradigmas contra hegemônicos, em nada se alteram as condições reais de reprodução da vida, mas, ora, não seria papel da ciência transformar a vida das pessoas? Ou seja, mudar a abordagem não modifica o papel que a ciência tem desempenhado como importante fator produtivo para reprodução do capital.

\section{ONTOLOGIA MATERIALISTA: A NECESSIDADE DE ENFRENTAR OS PROBLEMAS PELAS SUAS RAÍZES}

Neste tópico dividimos a exposição em dois momentos. No primeiro, recuperamos o trabalho de Habermas (1983) por conter a base da proposta de Paes de Paula (2016). No segundo, apresentamos, ainda que brevemente, o estatuto científico marxiano.

Paes de Paula (2015, p. 85) menciona em seu livro:

Não está no escopo do presente livro averiguar se esse movimento atribuído por Jürgen Habermas a Karl Marx é procedente, mas talvez a naturalização das leis econômicas não tenha sido culpa de Karl Marx [...] De qualquer modo, esse é o ponto de partida de Jürgen Habermas opor ao agir instrumental, um agir comunicativo e, perfilar ao lado do trabalho, a interação como parte fundamental da autoconstituição da espécie.

Ainda que Paes de Paula (2015) desconfie de que o ponto de partida de Habermas possa estar equivocado, ela, por não fazer parte de seus objetivos cognitivos, opta por assumir o equívoco argumentando que ele apenas creditou a crítica à pessoa errada (à Marx e não aos marxistas). Mas, se a compreensão de Habermas a respeito de Marx está em questionamento, não seria de responsabilidade axiológica (a partir da própria observação de Paes de Paula, sustentada pelas considerações de Hill) do pesquisador "escavar" o passado para avançar na produção do conhecimento no presente? Entendemos que sim, pois, justamente a escolha de Paes de Paula impõe a escavação na abordagem sociológica habermasiana o que a levaria à Marx. Porém a autora furta-se de seguir suas próprias recomendações, adotando os equívocos 
de Habermas enquanto elementos estruturantes de sua proposta, permitindo assim lançar a hermenêutica como ciência universal. Não nos furtaremos a escavação, por considerar, inclusive, que aquele autor também influencia o pensamento de outros estudiosos (BURRELL, 1994; SERVA, 1997a, 1997b, 2015; TENÓRIO, 1998; VIZEU, 2005, 2016; ALCÂNTARA, 2018) das ciências administrativas que se preocupam com as questões do saber.

\subsection{CRÍTICA DO ESTATUTO ONTOLÓGICO FUNDANTE DADO À LINGUAGEM AO LADO DO TRABALHO}

Habermas ao falar da reprodução da vida humana, que culmina no homo sapiens, é categórico: "trabalho e linguagem são anteriores ao homem e à sociedade." (1983, p. 118). Diferentemente de Habermas, Marx e Engels em A Ideologia Alemã (2007, pp.34-35) apontam a linguagem enquanto um momento do desenvolvimento do ser social e uma manifestação material da consciência, que se desdobra do ato ontológico:

A linguagem é tão antiga quanto a consciência - a linguagem é a consciência real, prática, que existe para os outros homens e que, portanto, também existe para mim mesmo; e a linguagem nasce, tal como a consciência, do carecimento, da necessidade de intercâmbio com outros homens. Desde o início, portanto, a consciência já é um produto social e continuará sendo enquanto existirem homens. (MARX; ENGELS, 2007, p. 34-35).

Para contrapor essa questão nos valemos de Fortes (2016, p. 47): “o homem é definido como um ser que se autorreproduz, deste modo, não há elementos anteriores à sua própria existência, um atributo transcendente que ponha a essência do humano como uma anterioridade necessária ao próprio mundo”.

Contudo, não é essa a compreensão que Habermas tem do pensamento de Marx, e por isso ressalta uma pressuposição da linguagem no processo evolutivo, portanto, o trabalho, visto sob o prisma do agir instrumental, não seria a categoria ontológica preponderante. A constituição da linguagem e a sua consequente articulação com o trabalho, sinteticamente, é a 
base conceptiva de sua teoria do agir comunicativo. A formação da linguagem e de suas mais diversas formas lógicas é vista pelo autor como o elemento primordial na sociabilidade humana. Habermas desenvolve seu argumento a partir da tradição racional-iluminista, apontando a racionalidade como sendo "a forma em que os sujeitos capazes de linguagem e ação fazem uso do conhecimento" (HABERMAS, 1999, p. 24), tendo pouca importância o modo como esse conhecimento é adquirido. Para Habermas, a partir da fala é possível um entendimento conceitual real e ampliado do que seria a "razão", pois somente esse movimento seria capaz de resgatar o potencial emancipatório da razão (manifestado na constituição de consensos racionais a partir da fala), sendo a fala e o discurso os determinantes últimos da razão e da emancipação da própria razão. Por faltar a Habermas a compreensão de Marx, ele dá primazia ao agir comunicativo, tese usada por Paes de Paula (2016) para sustentar o fazer da nova teoria do conhecimento.

Habermas (1983) também critica o conceito de totalidade social adotado por marxistas, cuja crítica se baseia na ideia da superestrutura concentrar todos os fenômenos sociais, o que impediria a concepção de um modelo segundo estratos, porque ignora a construção intersubjetiva de cada ser humano proporcionado pela via comunicativa. Sobretudo, a fala seria o ponto central, pois dela derivaria a construção racional do saber e nela estaria a chave para a transformação das interações sociais opressoras, por isso a crença na construção de um consenso comunicativo.

Em outras palavras, o estatuto ontológico habermasiano tem na linguagem o componente essencial da formação da sociabilidade, por conseguinte, pela intersubjetividade como gênese das relações entre os indivíduos. Habermas, na crítica, não se atentou para o exposto por Marx (2009, p. 45): “O modo de produção da vida material condiciona o processo de vida social, política e intelectual. Não é a consciência dos homens que determina o seu ser; ao contrário, é o seu ser social que determina sua consciência”. Portanto, até mesmo a linguagem é, antes, influenciada pela materialidade - como apresentado em trecho anterior. E isso não implica num determinismo estrutural, conforme quis demonstrar Habermas, pois estas circunstâncias materiais são igualmente condicionadas e condicionantes da vida social, os indivíduos fazem sua própria história e suas escolhas a partir das situações e circunstâncias postas (MARX; ENGELS, 2007; MARX, 2011), por isso Lukács (2010, 2012, 2013), a partir do pensamento marxiano, aponta para o pôr teleológico como essencial de toda práxis humana, que dele se desdobra o desenvolvimento de um campo de possibilidade - limitada pelas leis de causalidade social - que permite o desenvolvimento humano enquanto uma tendência, não enquanto uma determinação. 
Fortes (2016, p. 49) afirma que "o pôr teleológico é o veículo central do 'homem', a ‘categoria elementar específica' do ser social.”. E ainda sugere "o 'pôr teleológico' como a caracterização mais geral de toda atividade humana". Ademais, Fortes (2016) aponta que são igualmente formas particulares de pôr teleológico a política, a arte, a filosofia e etc., mas é na análise do trabalho que é possível compreender a forma mais integral dessa atividade. Essas formas de teleologias particulares deixam, de maneira evidente, como sugere Sartori (2010, p. 42), a "indissociabilidade das esferas do trabalho, tido como protoforma, e da interação humana baseada na comunicação", levando-se em consideração que, ao mesmo tempo, o trabalho depende das mais complexas mediações da práxis social.

Por que estamos fazendo essa digressão? Para chamar a atenção de que o real não é aquilo que apreendemos cognitivamente, mas aquilo que fazemos. A objetividade está posta, a despeito de termos ou não consciência dela, por outro lado, temos a possibilidade de termos consciência dela, mas essa não determina a primeira, é a primeira a condição de possibilidade da segunda.

O gnosiologismo, ao separar e isolar os objetos sociais, negando sua relação complexa e recíproca de determinações, perde a totalidade objetiva. Os aspectos do objeto são cindidos de sua integralidade criando dimensões parcelares e artificiais de estudo, através de uma construção mental de pressupostos e procedimentos que o circunscrevem. Recai na imposição/imputação subjetiva sobre a objetividade. Esse movimento, é justamente o que defende Paes de Paula (2016).

\begin{abstract}
Sustento que ao considerar um objeto empírico, o investigador deveria levar em conta os três tipos de interesse cognitivos que o circundam, fazendo uma escolha consciente, que deixe claras as limitações cognitivas que sofrerá. Ou então partir da perspectiva de que o interesse emancipatório guia a pesquisa a fim de mediar os interesses técnicos e práticos, o que aponta para uma nova forma de fazer ciência, levantada por Jürgen Habermas em Conhecimento e interesse. Logicamente, mesmo no caso em que esse esforço de integração de interesses for realizado, as preferências cognitivas irão se apresentar, e o grau em que cada interesse será contemplado tenderá a ser diferente, mas só fato de fazer uma pesquisa com esse tipo de consciência atribui um status crítico à produção do conhecimento. (p. 38).
\end{abstract}

Novamente, o objeto - e sua totalidade - é preterido pela autora que destaca a primazia das preferências cognitivas. Nesse sentido, como evitar a guerra entre paradigmas ou entre abordagens sociológicas se, em última instância, o preponderante são as preferências do pesquisador? Ou ainda, como explicar e apresentar soluções para os problemas reais, se estes estão a mercê das preferências cognitivas? Com essas indagações não queremos um retorno a ideia de neutralidade do pesquisador. Nós não desconsideramos que o sujeito que pesquisa tenha preferências, mas - e é isso que buscaremos tratar agora - consideramos que essas 
preferências podem determinar sobre qual problema se debruçar, não imputar às preferências ao problema concreto. Para evitar isso, e evitar igualmente uma volta à discussão weberiana, sugerimos a primazia do objeto sobre aquele que conhece.

\title{
3.2 A PRIMAZIA DO OBJETO: PARA AVANÇAR NA PRODUÇÃO DO CONHECIMENTO
}

De partida asseveramos que não pretendemos expor nenhum modelo para a construção de conhecimento. Não é nossa intenção nos debruçarmos exaustivamente no como, mas colocar alguns elementos pertinentes a diferença daquilo que se conhece. As reflexões sobre a gnosiologia nos permitiram observar que ela mesma se coloca limites quanto à explicação dos problemas sociais e, nesse sentido, seguir afiando e reconstruindo os instrumentos (métodos e técnicas) não parece ser a resposta requerida para a preocupação de autores/as analisados aqui como Guerreiro, Campos, Paes de Paula, dentre outros. Por isso, observamos a determinação ontoprática do pensamento e nesta rota traremos breves apontamentos sobre o estatuto científico marxiano, ou apenas, o método de Marx.

A abordagem científica marxiana é diferente do método científico que parte da dimensão gnosio-epistêmica (imputação/imposição subjetiva sobre o real): Marx, por sua apreensão ontológica materialista instauradora, trabalha em sua abordagem científica com o

primado do objeto. É este, em seu conjunto complexo de determinações, que pode "dizer" de si mesmo (ou seja, não se constrói objetos, não se faz imputação subjetiva). Há a posição definida de que o objeto deve e pode ser apreendido em sua integridade, em sua aparência e em sua essência, isto é, em sua totalidade. É, portanto, no sentido de apreensão da totalidade do objeto e dos vários complexos que o compõem e que existem objetivamente - sem imposição subjetiva - que a razão deve se mover, no sentido da apreensão do concreto em sua forma de concreto pensado.

\begin{abstract}
A investigação tem de se apropriar da matéria [stoff] em seus detalhes, analisar suas diferentes formas de desenvolvimento e rastrear seu nexo interno. Somente depois de consumado tal trabalho é que se pode expor adequadamente o movimento do real. Se isso é realizado com sucesso, e se a vida material é agora reproduzida idealmente, o observador pode ter a impressão de se encontrar diante de uma construção a priori. (MARX, 2013, p. 90).
\end{abstract}

A totalidade do objeto é a apreensão de seus elementos determinantes - em sua singularidade, particularidade e universalidade - e das conexões de reciprocidades dialéticas entre eles. De forma imediata, o objeto se apresenta ao pesquisador em sua aparência, revelando certos aspectos seja do complexo particular a qual pertence, ou dos complexos 
particulares do qual se distancia, seja da universalidade do qual é constituinte, seja em sua singularidade. Da aparência do fenômeno, do todo caótico, é que se parte, mas, para Marx, o objeto não dependente de pressupostos e procedimentos previamente delimitados; é a atividade da consciência que o reconhece. É a realidade concreta em sua lógica específica e processual que dão a possibilidade do filósofo/cientista, do sujeito cognitivo, chegar ao concreto pensado, por meio de abstrações.

Antes que os mais comprometidos epistemólogos nos questionem acerca do papel do sujeito nesta relação, precisamos evidenciar que a primazia do objeto sob o sujeito não implica em um apequenamento da razão humana, tampouco é uma redução da especulação ou da criatividade, ao revés, quanto mais complexo for o objeto mais intelectualmente preparado deve estar o pesquisador. A inversão, em vista disso, se dá na medida em que o trabalho da abstração tem como referência a própria realidade do objeto (em suas múltiplas determinações), e não apenas a intelecção do pesquisador.

Marx (2013, p. 113), no prefácio da segunda edição do Capital livro 1, nos informa que "[...] na análise das formas econômicas não podemos nos servir de microscópio nem de reagentes químicos. A força da abstração [Abstraktionskraft] deve substituir-se a ambos.". As abstrações são a exposição no campo das ideias das relações determinantes dos objetos. Por exemplo, no desenvolvimento das relações sociais, estabelecemos relações de troca, para as quais, em determinado momento, em função de determinadas características, algo assumiu a posição de mediador universal: o dinheiro. É o estudo do desenvolvimento histórico das relações de troca que alcançamos a possibilidade de descrever a categoria dinheiro - a abstração universal de um aspecto da relação. Gorender (2013, p. 61) explica: "Todo conceito abstrato fornece, portanto, o conhecimento de uma realidade cuja existência ele revela: conceito abstrato quer dizer, então, fórmula aparentemente abstrata, mas, na realidade, terrivelmente concreta pelo objeto que designa".

Ainda exemplificando, um estudo do sistema financeiro, cujo elemento mobilizador é o dinheiro, não pode, para ser apreendido em sua totalidade, ser efetivado segundos recortes feitos pelos financistas, em que o que está em consideração, pela aplicação de modelos, são, por exemplo, as taxas de rendimentos (MACHADO; MACHADO; CORRAR, 2009; RITTA et al, 2010). É necessário, para entender o sistema financeiro, capturá-lo em suas múltiplas funções no movimento de produção e circulação do capital e no movimento que alçou essa particularidade do todo para o centro das relações sociais hodiernas (dentro de um sistema de trocas capitalista). Os gráficos da bolsa podem ser a parte aparente do movimento, deles podemos partir, mas de modo algum eles são a essência do objeto em questão, de modo 
algum eles podem explicar o problema social da financeirização da economia. Seguir o movimento do dinheiro em suas transmutações universal, particular e singular específicas a esse complexo de trocas é uma tarefa que o real impõe ao pesquisador, mas que os administradores financeiros se furtam, por realizar pesquisas segundo seu interesse cognitivo ou, como disse Marx (2013, p. 85) ao se referir aos economistas políticos: “[...] por entender a ordem capitalista como a forma última e absoluta da produção social, em vez de um estágio historicamente transitório de desenvolvimento, a economia política só pode continuar a ser uma ciência enquanto a luta de classes permanecer latente ou manifestar-se apenas isoladamente".

Buscando contribuir com a apreensão do Método de Marx, salientamos alguns dos pontos considerados importantes por Chasin (2009). Vale ressaltar que o filósofo alemão concilia filosofia e ciência, porém essa conciliação não ocorre impulsionada por interesses cognitivos como postula Paes de Paula a partir de Habermas, no estatuto ontológico marxiano a reciprocidade entre ciência e filosofia engendram a própria acepção de como avançar na produção do conhecimento sobre a qual estamos discorrendo.

Destacamos, na sequência, quatro desses pontos:

(1) Fundação ontoprática do conhecimento - "ontoprático" é ter como ponto de partida a prática cotidiana, ou seja, partir da vivência cotidiana, somente a partir disso pode surgir alguma questão teórica, o ponto de vista "ontoprático" tem como pressuposto o concreto, da qual o indivíduo faz parte e do qual, pelo trabalho teórico, se afasta a partir de uma abstração, a prática cotidiana do ser social é o fundamento da concepção ontológica, mas não se esgota nela.

(2) Determinação social do pensamento - reconhecimento da presença da história na formação do pensamento, o desenvolvimento do ser social e da sociabilidade burguesa (formação e divisão das classes sociais) têm na história um importante campo resolutivo.

3) Teoria das abstrações - pelo fato de que a imediaticidade nos coloca em contato primeiro com o aparente, sua forma mais visível, é preciso se chegar à essência do objeto social para se estabelecer sua relação com o aparente (que não são distintos, essência e aparência são momentos de um mesmo processo), para tanto as abstrações são fundamentais. A lógica das abstrações permite ir até o cerne específico do objeto e um "voltar" para a análise da complexa relação social humana.

4) Lógica do concreto - compreensão da lógica que constitui o real, o cotidiano, o concreto, para a partir dele se compreender o objeto. Ressaltamos que estes pressupostos são caminhos complementares para a compreensão do fazer científico de Marx. 
Sobretudo, conforme Marx (2011), o concreto é concreto porque é o resultado de múltiplas determinações. E estas para serem apreendidas, necessitam ser capturas em seu desenvolvimento (historicidade das relações que a engendram - não se trata, portanto, de descrições históricas sobre empresas, grupos, ciência administrativa, etc.) e em sua lógica contraditória.

Sobre a contradição do real, Engels busca explicá-la a partir da dialética da natureza, contudo, como Lukács (2012) demonstrou, esse não é o caminho acurado, não por motivo da existência da dualidade entre essas duas esferas (natureza e sociedade), mas por considerar que a partir do salto qualitativo oportunizador da constituição do ser social, a humanidade se afasta - sem se independizar - das causalidades mudas que regem o ser inorgânico e o ser orgânico. A práxis humana, cuja protoforma é o trabalho, não é mais muda. O ser humano se autorreproduz pela atividade intencional. E, no ser social, da relação ativa entre os seres humanos, desdobram-se relações de causalidades sociais. Sob essas, diferente das causalidades da natureza, somente é possível observar tendências, e não inevitabilidades.

A lei da acumulação do capital, portanto, é uma tendência, pois se não forem alteradas as condições que a produzem, ela se impõe como determinante social gerador de acumulação de riqueza por um lado, e de pobreza por outro. Eis porque, para os marxistas, a supressão da propriedade privada dos meios de produção é uma necessidade: para que a tendência não siga sua realização. Ou seja, a contradição real colocada, que quanto mais riqueza os trabalhadores produzem, mais pauperizados se encontram, somente pode ser superada pela supressão das condições concretas que a geraram e não pela emancipação do pensamento da lógica dogmática. Não é, assim, o pensamento que é contraditório, mas o próprio movimento do real, tendo, sob o capital, a contradição essencial manifestada na relação capital-trabalho.

Nesse sentido, a utilização da razão na perspectiva individual do ser social, é, em seu maior grau dentro do capitalismo, o reconhecimento do conjunto de determinações que compõem a totalidade objetiva em que ele está inserido, o que significa que para certos indivíduos (sobretudo aqueles que necessitam da venda da sua força de trabalho para sobreviver) esse movimento possui o potencial de revelação da sua condição. Assim é, que a centralidade da razão dentro da história, possui limites de apreensão da totalidade objetiva, há possibilidade de perspectivas históricas em determinado momento acessarem mais a essência do real, o concreto, a verdade, o maior número possível de determinações que circunscrevem o objetivo. Porém, para a perpetuação do sociometabolismo do capital a produção do conhecimento não pode chegar à raiz dos problemas sociais, ao preço de revelar a 
necessidade da revolução social, caso o faça. Eis porque o pensamento radical, aquele que vai a raiz (essência) do problema é tão rechaçado nas ciências hodiernas.

Tal rechaço, em geral, se vale da justificativa epistemológica. A produção do conhecimento gerado a partir da primazia da materialidade das relações resulta na demanda por revoluções sociais (revoluções no sentido de mudança de qualidade da coisa) e, isso entra em contradição com os interesses da classe capitalista, logo, há a necessidade de recusar pesquisas com esta vertente. Observamos, assim, o argumento epistemológico sendo trazido à tona, julga-se o conhecimento radical com a métrica dos paradigmas ou das abordagens sociológicas.

\section{CONSIDERAÇÕES FINAIS}

Nos propomos a analisar os limites das propostas gnosiológicas frente a resolução da guerra paradigmática. Apontamos, após análise interna da proposta de Paes de Paula, os avanços e limitações no que se refere à guerra paradigmática. Pontuamos que essa adoção apenas retroalimenta tal peleja, demonstramos que argumentos epistemológicos são acionados em nome dos interesses de legitimar e/ou aperfeiçoar os processos de produção de um determinado conhecimento, que necessitam refutar a prática do conhecer que vai às raízes dos problemas sociais. E, no caso, ir a raiz é colocar o processo de produção do conhecimento para além das discussões gnosiológicas e tomar a condição material dessa produção.

Ratificamos a impotência dos produtos das matrizes epistemológicas frente ao método marxiano. O que não significa uma impossibilidade de um pesquisador marxista fazer uso das descrições produzidas nas distintas abordagens sociológicas, ora, a aparência também faz parte do objeto, sendo este o movimento que fizemos neste ensaio: apoiamo-nos na proposta do CME e em textos que advogam a necessidade de resgatar o poder explicativo do conhecimento produzido na Ciência Administrativa, para destacar que a perspectiva gnosiológica não é a resposta necessária a tal demanda, posto que ela não supera o aspecto aparente do fenômeno em sua parcialidade, determinado, como coloca Paes de Paula (2015), pelos interesses cognitivos. Essa característica do fazer ciência (aparência do fenômeno e sua parcialidade) é o que nos permite encontrar relativa correspondência entre o conhecimento acerca do objeto e o objeto (pois aparência é um dos aspectos do fenômeno, como já observamos acima). Porém, o objeto segue se impondo à observação do sujeito para além das limitadas teorias desenvolvidas, mas ao invés de deixarmos o objeto "nos dizer" como nossa 
razão pode torná-lo concreto pensado, voltamo-nos para nossos instrumentos da "razão" ou os negamos de vez (irracionalismos) na tentativa de nos mantermos na visada subjetiva, isto é, na parcialidade da gnosiologia.

Diante das demandas cada dia mais frequentes que se impõem aos pesquisadores acerca da necessidade de discutir o aumento da produtividade do trabalho e sua relação com o processo de valorização e com os problemas sociais engendrados, diante do adoecimento de pesquisadores e trabalhadores em geral, diante da produção de estudos que pouco contribuem com a emancipação política e humana, visto que sua finalidade é garantir o lucro de uma pequena parcela da população, é primordial que uma crítica radical seja o horizonte das pesquisadoras e dos pesquisadores aqui e alhures. Sobretudo, sustentamos que práxis científica deve ter por horizonte não o interesse pela emancipação nos termos de Paes de Paula a partir de Habermas, mas sua necessidade real. Não a emancipação do pensamento, mas a emancipação real.

O método de Marx avança igualmente no que se refere à transdisciplinaridade, interdisciplinaridade, multidisciplinaridade, como tem sido defendido pelos epistemólogos. A perspectiva ontológica busca a totalidade do fenômeno, por isso não se aprisiona a disciplinas, pois o real se apresenta como um todo complexo e, desta maneira, não separa os problemas em áreas de conhecimento. As disciplinas são engendradas pela imputação da razão ao real (pelos recortes que realizamos), suas fronteiras são ilusórias e, por isso, apenas sob a perspectiva epistemológica é possível reconhecê-las. O problema da disciplinaridade é um falso problema, ou melhor, é um problema de divisão social do trabalho, e não da natureza do objeto estudado. É o motivo pelo qual justificamos que a totalidade objetiva não se relaciona com: cooperação entre os paradigmas sociológicos, reconstruções epistêmicas, transdisciplinaridades e muito menos com a integração de interesses. Pois não se trata de um ato singular e subjetivo, tampouco será resultado de consensos discursivos que produzem uma verdade relativizada sobre os objetos. Não se trata de subtrair determinados elementos do real por ele não ser comportado pelo objeto construído gnosiologicamente, tampouco trata-se de isolar percepções de sujeitos singulares e descrevê-las, tipologizá-las, etc. Muito menos trata-se de atribuir a priori uma natureza qualitativa ou quantitativa ao objeto. Os objetos são expressos quantitativa e qualitativamente na realidade das relações sociais, apreender a totalidade do objeto demanda, portanto, não imputar gnosiologicamente a ele uma das naturezas.

Por fim, destacamos que a tarefa dos pesquisadores comprometidos com a produção de um conhecimento que concomitantemente explique o real e permita intervenções passíveis 
de mudanças efetivas está para além de superar guerras paradigmáticas. Seria ingênuo supor, também, que apenas uma mudança de abordagem (da gnosiologia para a ontologia) seria suficiente - isoladamente - para transformar a realidade, não o é, pois a lógica que rege as relações humanas é a do valor em seu movimento alienante e desumanizador, contudo, ao tomarmos por horizonte o devir de uma sociabilidade para além do capital, faz-se prioritário transformar radicalmente tanto nossas práticas quanto nossa consciência, os pores teleológicos também estão na filosofia, na ciência, nas artes etc, assim, o exercício de uma ciência que ataque a raiz dos problemas é sine qua non para o processo de transformação social.

Diversos limites se colocam a essa tarefa, seja pelos motivos já discutidos ou pelas contradições da relação capital-trabalho, e aprendemos desde muito cedo a fazer ciência de uma maneira, contudo, fazer diferente requer um novo esforço. Como nos alertou Marx (2014, p. 617) "na análise objetiva do mecanismo capitalista, certos estigmas que se ligam a ele com extraordinária tenacidade não podem nos servir de subterfúgio para eliminar dificuldades teóricas.”, ou dito de outra forma, com esse escrito, que nos inseriu na Guerra Paradigmática, buscamos não nos refugiar nessa tática estigmatizada de posições de guerrilha para justificar nossas dificuldades teóricas. Ao contrário, demonstramos com esse texto que refinar argumentos epistemológicos recrudesce a Guerra ainda que seja por meio do sutil discurso da tolerância. Ao adentramos na disputa, tornou-se necessário assumir que o conhecimento do real não ocorre por meio de tomada de posições entre quadrantes ou círculos. A tomada de decisão fundamental é a de ir ou não à raiz dos problemas sociais e, se a posição é por conhecer o real como ele é, ou seja, como movimento do real concreto resultante de múltiplas determinações, não há como permanecer nessa guerra paradigmática, posto ser ela apenas um dos muitos subterfúgio engendrado pelo mecanismo produtivo da ciência em prol dos interesses do capital. Ao afirmamos isso, nos retiramos do campo de batalha concisos da necessidade de seguir rompendo com as amarras que nos prende ao modus operandi da ciência burguesa, tarefa que, como nos lembra Marx, não traz consigo nenhuma facilidade, posto que "todo começo é difícil, e isso vale para toda ciência" (MARX, 2013, p. 77).

\section{REFERÊNCIAS}

ALCÂNTARA, V. de C.; PAIVA, A. L. de; BRITO, M. J. de. Desvelando "caixas-pretas" dos textos de estratégia: uma abordagem baseada na hermenêutica crítica. O\&S, v.25, n.84, p.30-49, 2018. 
BARBOSA, M. A. C.; SANTOS, J. M. L. dos; MATOS, F. R. N. e ALMEIDA, A. M. B. Nem só de debates epistemológicos vive o pesquisador em administração: alguns apontamentos sobre disputas entre paradigmas e campo científico. Cad. EBAPE.BR, v. 11, n. 4, p. 636-651, 2013.

BURKE, P. Uma história social do conhecimento - I: de Gutenberg a Diderot. Rio de Janeiro: Zahar, 2003.

BURRELL, G. Ciência normal, paradigmas, metáfora discursos e genealogia da análise. In: CLEGG, S.; HARDY, C.; NORD, W.; CALDAS, M.; FACHIN, R.; FISCHER, T. (orgs.)

Handbook de Estudos Organizacionais. Modelos de Análise e Novas Questões em Estudos Organizacionais (Volume 3). São Paulo: Atlas, 1998. p. 439-462.

BURRELL, G.; MORGAN, G. Sociological Paradigms and Organisational Analysis. Elements of the Sociology of Corporate Life. Vermont: Ashgate, 1979.

BURRELL, G.; MORGAN, G. Modernism, Postmodernism and Organizational Analysis 4: The Contribution of Jürgen Habermas. Organization Studies, v. 15, n. 1, p. 1-45, 1994. CAMPOS, A. M. S. M. Contribuição para a o resgate da relevância do conhecimento para a administração. Physis. Revista de Saúde Coletiva, Rio de Janeiro, v. 7, n. 2, p. 25-35, 1997. CHASIN, J. Marx: Estatuto ontológico e resolução metodológica. São Paulo: Boitempo, 2009.

CNPq - Conselho Nacional de Desenvolvimento Científico e Tecnológico. Painel de Investimentos. http://cnpq.br/painel-de-investimentos. Acesso em 05 fev. 2018.

DUAYER, M. Filosofía de la ciencia y crítica ontológica: verdad y emancipación. Disponível em: http://www.herramienta.com.ar/revista-herramienta-n-55/filosofia-de-la-ciencia-ycritica-ontologica-verdad-y-emancipacion. Acesso em: 29 mai. 2018.

FARIA, J. H. de. Epistemologia crítica do concreto e momentos de pesquisa: uma proposição para os estudos organizacionais. RAM, v.16, n.5, p.15-40, 2015.

FARIA, J. H. de. Epistemologia e método em Hegel: a fenomenologia e a ciência da lógica. In: EnANPAD, 2016, Salvador. Anais eletrônicos... Salvador: ANPAD, 2016. Disponível em:

http://www.anpad.org.br/ anpad/ventos.php?cod_evento $=1 \& \operatorname{cod}$ evento edicao $=83 \& \operatorname{cod}$ ed icao $\operatorname{subsecao}=1302 \&$ cod edicao trabalho=21312. Acesso em: 10 jan. 2018.

FERRAZ, D. L. S.; MUELLER, R. R. Assistencialismo e Empreendimentos Populares de Trabalho: Relações Necessárias para a Erradicação da Pobreza?. Revista Eletrônica Gestão e Sociedade, v. 7, p. 186-219, 2013. 
FERRAZ, D. L. S. A administração de recursos humanos como conhecimento que constitui uma consciência de classe para o capital. Revista Brasileira de Administração Política, v. 9, n. 2, 2016.

FORTES, R. V. As três determinações fundamentais da análise lukacsiana do trabalho: modelo das formas superiores, prioridade ontológica e abstração isoladora - Crítica da ideia de centralidade do trabalho em Lukács. Revista Verinotio, n. 22, .44-75, 2016.

HABERMAS, J. Para a reconstrução do materialismo histórico. Brasília: Editora Brasiliense, 1983.

HABERMAS, J. Teoría de la acción comunicativa I: Racionalidad de la acción y racionalización social. Madrid: Taurus, 1999.

HILL, M. R. Epistemology, Axiology, and Ideology in Sociology. Mid-American Review of Sociology, v. 9, n. 2, p. 59-77, 1984.

KUHN, T. S. A Estrutura das Revoluções Científicas. São Paulo: Perspectiva, 2007.

LUKÁCS, G. Para uma ontologia do ser social I. São Paulo: Boitempo, 2012.

LUKÁCS, G. Para uma ontologia do ser social II. São Paulo: Boitempo, 2013.

LUKÁCS, G. Prolegômenos para uma ontologia do ser social: questões de princípios para uma ontologia hoje tornada possível. São Paulo: Boitempo, 2010.

MACHADO, M. R.; MACHADO, M. A. V.; CORRAR, L. J. Desempenho do Índice de Sustentabilidade Empresarial (ISE) da Bolsa de Valores de São Paulo. Revista Universo Contábil, v. 5, n. 2, p. 24-38, 2009.

MARX, K.; ENGELS, F. A Ideologia Alemã. São Paulo: Boitempo, 2007.

MARX, K. Contribuição à crítica da economia política. São Paulo: Expressão Popular, 2009.

MARX, K. O 18 de Brumário de Luís Bonaparte. São Paulo: Boitempo, 2011.

MARX, K. O capital: crítica da economia política: livro I: o processo de produção do capital. São Paulo: Boitempo, 2013.

MARX, K. O capital: crítica da economia política: livro II: o processo de circulação do capital. São Paulo: Boitempo, 2014.

BRASIL. MEC - Ministério da Educação. Censo da Educação 2014. Disponível em: http://portal.inep.gov.br/informacao-da-publicacao//asset_publisher/6JYIsGMAMkW1/document/id/636024. Acesso em: 5 de jan. de 2017. PAES DE PAULA, A. P. Repensando os Estudos Organizacionais. Por uma Nova Teoria do Conhecimento. Rio de Janeiro: EdFGV, FAPEMIG, 2015. 
PAES DE PAULA, A. P. Para Além dos paradigmas nos estudos organizacionais: o círculo das matrizes epistemológicas. Cad. EBAPE.BR, v. 14, n. 1, p. 24-46, 2016.

PAÇO-CUNHA, E. Gênese, razoabilidade e formas mistificadas da relação social de produção em Marx: a organização burocrática como abstração arbitrária. Tese (Doutorado). UFMG, Belo Horizonte, 2010.

RITTA, C. O.; ENSSLIN, S. R.; RONCHI, S. H. e ENSSLIN, S. R. A evidenciação dos ativos intangíveis nas empresas brasileiras: empresas que apresentaram informações financeiras à Bolsa de Valores de São Paulo e Nova York em 2006 e 2007. Revista Eletrônica de Ciência Administrativa, v. 9, n. 1, p. 62-75, 2010. SARTORI, V. B. Lukács e a crítica ontológica ao direito. São Paulo: Cortez, 2010. SANTOS, E. L. O campo científico da administração: uma análise a partir do círculo das matrizes teóricas. Cad. EBAPE.BR, v. 15, n. 2, p. 209-228, 2017.

SCUSSEL, F. B. C. Poder, paradigmas e domínio na pesquisa em marketing no Brasil: uma análise da produção nacional da disciplina a partir das matrizes epistêmicas. Administração: Ensino e Pesquisa, v. 18, n. 3, p. 518-557, 2017.

SERVA, M. Abordagem substantiva e ação comunicativa: uma complementaridade frutuosa para a teoria das organizações. Revista de Administração Pública, v. 31, n. 2, p. 108-134, 1997a.

SERVA, M. A racionalidade substantiva demonstrada na prática administrativa. RAE, v. 37, n. 2 , p. $18-30,1997 b$.

SERVA, M. Epistemologia e Sociologia da Ciência da Administração. Cad. EBAPE.BR, v.11, n.4, p.500-502, 2013.

SERVA, M. Epistemologia da administração no Brasil: o estado da arte. Cad. EBAPE.BR, v. 15, n. 4, p. 741-750, 2017.

SERVA, M.; CAITANO, D.; SANTOS, L.; SIQUEIRA, G. A análise da racionalidade nas organizações - um balanço do desenvolvimento de um campo de estudos no Brasil. Cad. EBAPE.BR, v.13, n.3, p.414-437, 2015.

SIEGLER, J.; BIAZZIN, C.; FERNANDES, A. R. Fragmentação do conhecimento científico em Administração: uma análise crítica. RAE, v.24, n.3, p.254-267, 2014.

TENÓRIO, F. Gestão social: uma perspectiva conceitual. Revista de Administração Pública, v. 32, n. 5, p. 7-23, 1998.

VIZEU, F. Ação comunicativa e estudos organizacionais. RAE, v. 45, n. 4, p. 10-21, 2005. VIZEU, F.; MACADAR, M. A.; GRAEML, A. R. Produtivismo acadêmico baseado em uma perspectiva habermasiana. Cad. EBAPE.BR, v. 14, n. 4, p. 984-1000, 2016. 